Gut, 1982, 23, 507-512

\title{
Changes in intestinal alkaline phosphatase activity in cholera toxin-treated rats
}

\author{
S MIURA*, H ASAKURA, T MORISHITA, T HIBI, \\ Y MUNAKATA, K KOBAYASHI, and M TSUCHIYA $\dagger$ \\ From the Department of Internal Medicine, School of Medicine, Keio University, Tokyo, Japan
}

SUMMARY It is conceivable that brush border enzyme activities of the intestinal mucosa will change when bacterial toxins are exposed to the intestinal microvillous membranes. The effect of cholera toxin on the activity of intestinal alkaline phosphatase in rats was therefore determined in the intestinal mucosa by the histochemical method as well as in intestinal lymph by using lymph fistulated-rats. Activity of intestinal alkaline phosphatase in the intestinal mucosa and lymphatics changed biphasically after the oral administration of cholera toxin to rats. For the first three hours after the administration of cholera toxin it was depressed; it then increased and at eight hours reached a maximum. These changes in the activity of intestinal alkaline phosphatase were prevented by the administration of chlorpromazine, a known inhibitor of adenylate cyclase activity.

Recent studies have shown that cholera toxin stimulates an adenylate cyclase activity of intestinal mucosa, resulting in an increased concentration of mucosal cyclic $3^{\prime}, 5^{\prime}$-adenosine monophosphate (CAMP). ${ }^{12}$ It is also clear that this nucleotide is related to the massive isotonic secretion of the intestine induced by cholera toxin and the diarrhoea associated with it. ${ }^{3}$ Little is known, however, about the changes of glycoproteins in intestinal mucosa in cholera toxin induced diarrhoea. It has recently been reported that cholera toxin binds to certain glycoprotein receptors of rat intestinal microvillous membranes, which have a similar carbohydrate sequence to $\mathrm{GM}_{1}$ ganglioside, a known specific glycolipid receptor for cholera toxin. ${ }^{4}$ Another study has reported that cholera toxin induced glycoprotein secretion of rabbit small intestine. ${ }^{5}$ It is therefore conceivable that certain glycoproteins, as brush border enzymes of the intestinal mucosa, will change after attachment of cholera toxin to the intestinal microvillous membranes.

Intestinal alkaline phosphatase is a representative brush border enzyme of the intestine. Although its physiological function is not yet fully known, this

* Address for correspondence: Soichiro Miura, Department of Interna Medicine, School of Medicine, Keio University 35 Shinanomachi, Shinjukuku, Tokyo 160, Japan.

+ Address for requests for reprints: Masaharu Tsuchiya, Professor of Internal Medicine, School of Medicine, Keio University 35 Shinanomachi, Shinjukuku, Tokyo 160 , Japan.

Received for publication 2 November 1981 enzyme may play some role in the transport of several substances, such as long chain fatty acids and calcium in the intestinal mucosa. ${ }^{6-8}$ There have, however, been few studies on the changes of intestinal alkaline phosphatase activity by exposure to cholera toxin. ${ }^{9}$ The present study was therefore undertaken (1) to assess the biochemical and histochemical changes in intestinal alkaline phosphatase activity by exposure to cholera toxin and (2) to determine whether the changes of intestinal alkaline phosphatase activity are related to the rise in CAMP levels in the intestinal mucosa, using chlorpromazine, a known inhibitor of adenylate cyclase activity. ${ }^{10}$

\section{Methods}

MATERIALS

Male Wistar rats weighing about $300 \mathrm{~g}$ were used for the experiments. Purified cholera toxin was purchased from the Chemo-Sero-Therapeutic Research Institute (Kumamoto, Japan).

In order to study the effect of cholera toxin on mucosal production of CAMP, $10 \mu \mathrm{g}, 100 \mu \mathrm{g}$, and $1000 \mu \mathrm{g}$ of the toxin dissolved in $1 \mathrm{ml}$ Tris buffer solutions, $\mathrm{pH} 8.0$, were instilled into the duodenum of animals after intraperitoneal pentobarbitone anaesthesia $(50 \mathrm{mg} / \mathrm{kg}$ of body weight). Control animals were treated with same buffer solutions only. Three, six, nine, 12, and 24 hours after the 
administration of cholera toxin, the luminal contents of the total small intestine and the mucosal concentration of CAMP were measured. Luminal fluid contents were expressed as microlitres per centimetre of small intestine in length. For mucosal CAMP determination, the upper jejunal mucosa was removed by scraping and the scrapings were then homogenised in ice-cold $6 \%$ trichloroacetic acid. The homogenate was centrifuged and the supernatant was extracted with water-saturated ethyl ether and then dried. The residues were redissolved in acetate buffer solutions. CAMP was determined by radioimmunoassay using CAMP kit 125 (Hoechst) and was expressed as pmoles per milligram of the mucosal protein as determined by the method of Lowry et al. ${ }^{11}$

Alkaline phosphatase activity of the intestinal mucosa after exposure to cholera toxin was also investigated histochemically. Before and three, six, nine, and 24 hours after the administration of $100 \mu \mathrm{g}$ or $1000 \mu \mathrm{g}$ cholera toxin into the duodenum of rats, $0.5 \mathrm{~cm}^{3}$ specimens of jejunal segment were resected from the upper jejunum $5 \mathrm{~cm}$ distal to the ligament of Treitz. Specimens were fixed in formol calcium solutions for 24 hours at $4^{\circ} \mathrm{C}$ and then transferred to cold $0.88 \mathrm{M}$ gum sucrose solutions. They were embedded in gelatine and sectioned by a cryostat. Sections were stained using the method of Watanabe and Fishman. ${ }^{12}$

Alkaline phosphatase activity of intestinal lymph was also determined using lymph-fistulated rats. After intraperitoneal pentobarbitone anaesthesia, the main mesenteric lymphatic duct near the cisterna chyli was cannulated for the collection of intestinal lymph. After the operation, animals were kept in Bollman's cage ${ }^{13}$ and normal saline was given intravenously at the rate of $2.4 \mathrm{ml} / \mathrm{h}$ in order to maintain a lymph flow to the end of the experiments. Experiments started 16-20 hours after the operation. After the administration of $10 \mu \mathrm{g}, 100$ $\mu \mathrm{g}$, or $1000 \mu \mathrm{g}$ of cholera toxin into the duodenum of rats, intestinal lymph was collected continuously at one-hour intervals for 24 hours. Alkaline phosphatase activity in intestinal lymph was determined by the method of Kind and King. ${ }^{14}$ Lymph samples obtained from both control and cholera toxin-treated rats were subjected to electrophoresis on Agarose gels to determine the isoenzyme of alkaline phosphatase. ${ }^{15}$

Chlorpromazine $20 \mu \mathrm{g} / \mathrm{g}$ of body weight was injected intramuscularly at one-hour intervals from one hour before to five hours after the administration of cholera toxin to rats.

\section{Results}

\section{FLUID ACCUMULATION AND MUCOSAL CAMP} CONCENTRATION

Cholera toxin induced a marked accumulation of fluid in the small intestinal tract and a significant increase in CAMP levels in the jejunal mucosa (Table 1). Six hours after the administration of cholera toxin, luminal contents were moderately increased from the control value by $10 \mu \mathrm{g}$, and markedly increased by $100 \mu \mathrm{g}$ and $1000 \mu \mathrm{g}$. Chlorpromazine reduced cholera toxin-induced fluid accumulation significantly and its values were statistically not significant from controls. CAMP levels in jejunal mucosa were significantly increased six hours after the administration of $100 \mu \mathrm{g}$ and 1000 $\mu \mathrm{g}$ of cholera toxin. Chlorpromazine treatment also prevented these rises in CAMP levels.

A profile of the time course of events after the administration of cholera toxin is summarised in Table 2. Cholera toxin-induced fluid accumulation was demonstrated three hours after the administration of the toxin and reached its maximum by six hours. Three hours after exposure to cholera toxin there was an increase in tissue CAMP levels. The maximum increase in CAMP was noted six hours after exposure to cholera toxin and continued its rise to 12 hours after exposure. A slight increase of CAMP in jejunal mucosa was still found 24 hours after exposure to cholera toxin.

Table 1 Fluid accumulation of small intestinal tract and jejunal mucosal CAMP levels in rats six hours after cholera toxin administration: dose response and effect of chlorpromazine (CPZ)*

\begin{tabular}{|c|c|c|c|c|c|c|}
\hline & \multicolumn{6}{|c|}{ Dose of cholera toxin $(\mu g)$} \\
\hline & Control & 10 & 100 & 1000 & $100+C P Z$ & $1000+C P Z$ \\
\hline $\begin{array}{l}\text { Luminal contents }(\mu \mathrm{l} / \mathrm{cm} \text { of small intestine) } \\
\mathrm{p} \text { values } \\
\text { CAMP levels }(\mathrm{pmol} / \mathrm{mg} \text { mucosal protein) } \\
\text { p values }\end{array}$ & $\begin{array}{l}5 \cdot 3 \pm 0 \cdot 6 \\
3 \cdot 9 \pm 0 \cdot 2\end{array}$ & $\begin{array}{l}27 \cdot 5 \pm 7 \cdot 1 \\
<0 \cdot 05 \\
4 \cdot 6 \pm 0 \cdot 5 \\
\text { NS }\end{array}$ & $\begin{array}{l}83 \cdot 0 \pm 2 \cdot 5 \\
<0 \cdot 001 \\
8 \cdot 2 \pm 0 \cdot 5 \\
<0 \cdot 001\end{array}$ & $\begin{array}{l}116 \cdot 2 \pm 6 \cdot 6 \\
<0 \cdot 001 \\
9 \cdot 1 \pm 0 \cdot 9 \\
<0 \cdot 001\end{array}$ & $\begin{array}{l}9 \cdot 7 \pm 3 \cdot 3 \\
\text { NS } \\
4 \cdot 1 \pm 0 \cdot 5 \\
\text { NS }\end{array}$ & $\begin{array}{l}16 \cdot 3 \pm 6 \cdot 1 \\
\text { NS } \\
4 \cdot 3 \pm 0 \cdot 2 \\
\text { NS }\end{array}$ \\
\hline
\end{tabular}

* Cholera toxin was administered intraduodenally into the non-ligated small intestine of rats. CPZ $20 \mu \mathrm{g} / \mathrm{g}$ of body weight was injected intramuscularly at one-hour intervals from one hour before to five hours after the administration of cholera toxin. Results shown are the mean \pm SEM of six experiments. NS =statistically not significant $(p>0 \cdot 05)$ 
Table 2 Effect of cholera toxin on fluid accumulation of small intestinal tract and jejunal mucosal CAMP levels in rats: profile of time course after cholera toxin administration $(100 \mu \mathrm{g})^{*}$

\begin{tabular}{|c|c|c|c|c|c|c|}
\hline & \multicolumn{6}{|c|}{ Hours after administration of $C T$} \\
\hline & Control & 3 & 6 & 9 & 12 & 24 \\
\hline $\begin{array}{l}\text { Luminal contents }(\mu \mathrm{l} / \mathrm{cm} \text { of small intestine) } \\
\mathrm{p} \text { values } \\
\text { CAMP levels ( } \mathrm{pmol} / \mathrm{mg} \text { mucosal protein) } \\
\text { p values }\end{array}$ & $\begin{array}{l}5 \cdot 3 \pm 0 \cdot 6 \\
3 \cdot 9 \pm 0 \cdot 2\end{array}$ & $\begin{array}{l}35 \cdot 3 \pm 2 \cdot 9 \\
<0 \cdot 001 \\
6 \cdot 0 \pm 0 \cdot 9 \\
<0.05\end{array}$ & $\begin{array}{l}83 \cdot 0 \pm 2 \cdot 5 \\
<0 \cdot 001 \\
8 \cdot 2 \pm 0 \cdot 5 \\
<0 \cdot 001\end{array}$ & $\begin{array}{l}53 \cdot 8 \pm 1 \cdot 9 \\
<0 \cdot 001 \\
8 \cdot 1 \pm 0 \cdot 6 \\
<0 \cdot 001\end{array}$ & $\begin{array}{l}27 \cdot 2 \pm 2 \cdot 7 \\
<0 \cdot 001 \\
8 \cdot 0 \pm 0 \cdot 3 \\
<0 \cdot 001\end{array}$ & $\begin{array}{l}12 \cdot 0 \pm 2 \cdot 8 \\
<0 \cdot 01 \\
6 \cdot 0 \pm 0 \cdot 9 \\
<0 \cdot 05\end{array}$ \\
\hline
\end{tabular}

HISTOCHEMICAL STUDY OF ALKALINE

PHOSPHATASE ACTIVITY OF INTESTINAL MUCOSA

(Table 3)

Before the administration of cholera toxin, a strong enzyme activity of alkaline phosphatase was demonstrated on the brush border of villi. A slight positive reaction was observed in the lamina propria (Fig. 1A). These alkaline phosphatase activities of villi decreased three hours after exposure to cholera toxin, and there was no intense activity of alkaline phosphatase in the intestinal mucosa at this time (Fig. 1B). Six hours after the administration of cholera toxin, the intestinal alkaline phosphatase activity began to recover on the brush border and in the lamina propria of the mucosa, while, nine hours after, an intense alkaline phosphatase activity appeared again on the brush border of the villi. It is noteworthy that an intense intestinal alkaline phosphatase activity was also observed in the lamina propria and submucosal lymphatics, as if it was transferred to lymphatics nine hours after the administration of cholera toxin (Fig. 1C). Twentyfour hours afterwards, however, these changes reverted to the states that existed before exposure to the toxin. Chlorpromazine inhibited these changes of alkaline phosphatase activity of the intestinal

Table 3 Histochemical study of intestinal alkaline phosphatase activity before and after administration of cholera toxin in rats: effect of chlorpromazine (CPZ)

\begin{tabular}{|c|c|c|c|c|c|c|}
\hline & \multirow{2}{*}{$\begin{array}{l}\text { Before } \\
\text { adminis- } \\
\text { tration }\end{array}$} & \multicolumn{5}{|c|}{ After $(h)$} \\
\hline & & 3 & 6 & 9 & 24 & $\begin{array}{l}+C P Z \\
6\end{array}$ \\
\hline \multicolumn{7}{|l|}{ CT $100 \mu \mathrm{g}$} \\
\hline Brush border & ++ & + & + & ++ & ++ & ++ \\
\hline Stroma & + & - & + & ++ & + & + \\
\hline \multicolumn{7}{|l|}{ CT $1000 \mu \mathrm{g}$} \\
\hline Brush border & ++ & + & + & ++ & ++ & ++ \\
\hline Stroma & + & - & + & $+t$ & + & + \\
\hline
\end{tabular}

Activity of alkaline phosphatase: - absent, + slightly present, ++ intensely present. mucosa after the administration of cholera toxin, and also six hours after administration. There was still a strong enzyme activity of alkaline phosphatase on the brush border of villi as seen before the administration of the toxin. These histological changes are summarised in Table 3.

\section{ACTIVITY OF ALKALINE PHOSPHATASE IN}

INTESTINAL LYMPH

Alkaline phosphatase zymograms of intestinal lymph showed that all of these activities were the intestinal types of alkaline phosphatase (Fig. 2). An intestinal alkaline phosphatase activity of intestinal lymph after the administration of $100 \mu \mathrm{g}$ and 1000 $\mu \mathrm{g}$ of cholera toxin changed biphasically and correlated well with histochemical observations. When $10 \mu \mathrm{g}$ of cholera toxin was administered, however, no significant changes in the activity of alkaline phosphatase in intestinal lymph were observed. Before the administration of cholera toxin, alkaline phosphatase output in intestinal lymph was $14.4 \pm 1.8\left(\right.$ mean \pm SEM) $\mathrm{KAU} \times 10^{-2} / \mathrm{h}$. Intestinal alkaline phosphatase activity was depressed temporarily by the first three hours after cholera toxin was administered and intestinal alkaline phosphatase output was $9 \cdot 1 \pm 1.3 \mathrm{KAU} \times 10^{-2} / \mathrm{h}$ $(0.01<\mathrm{p}<0.05)$ with $100 \mu \mathrm{g}$ of cholera toxin, and $9.0 \pm 0.9 \mathrm{KAU} \times 10^{-2} / \mathrm{h}(0.01<\mathrm{p}<0.05)$ with $1000 \mu \mathrm{g}$ of cholera toxin at two hours. But after that intestinal alkaline phosphatase activity began to rise four hours after the administration of cholera toxin. At eight hours its values reached a maximum of activity about three times as much as before the administration of the toxin, $37 \cdot 1 \pm 3.8 \mathrm{KAU} \times 10^{-2} / \mathrm{h}$ $(\mathrm{p}<0.001)$ with $100 \mu \mathrm{g}$, and $51.6 \pm 4.6 \mathrm{KAU} \times 10^{-2} / \mathrm{h}$ $(\mathrm{p}<0.001)$ with $1000 \mu \mathrm{g}$ of cholera toxin. These increases in intestinal alkaline phosphatase began to decline after reaching maximal rises and returned to control values in 24 hours. When rats were treated with chlorpromazine, however, no significant change in the activity of alkaline phosphatase in intestinal lymph was found even after the administration of cholera toxin. At two hours after toxin 


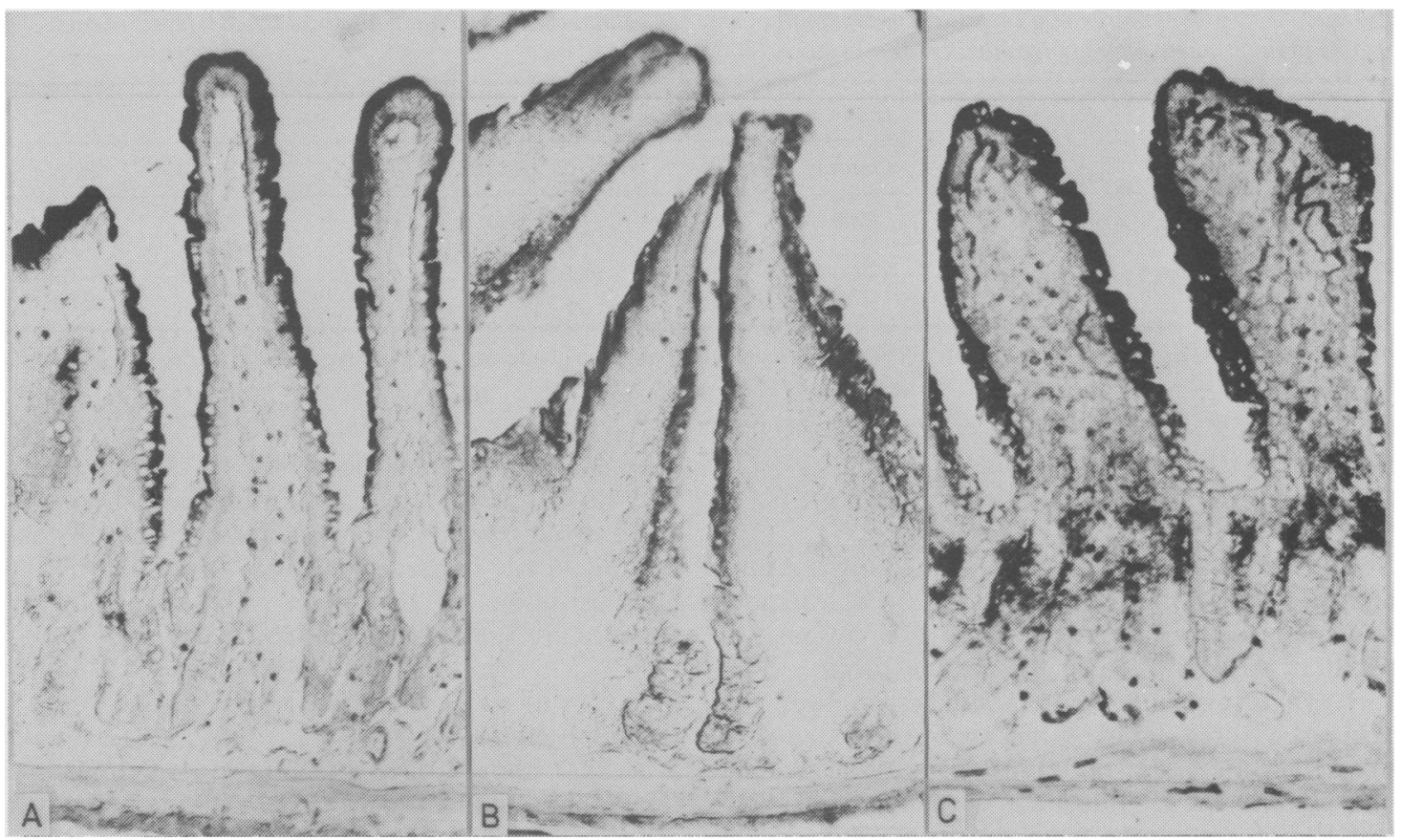

Fig. 1 Histochemistry of alkaline phosphatase activity of the jejunum after the administration of $100 \mu \mathrm{g}$ cholera toxin to rats. A: before, B: three hours after, C: nine hours after the administration of cholera toxin. $\times 160$.

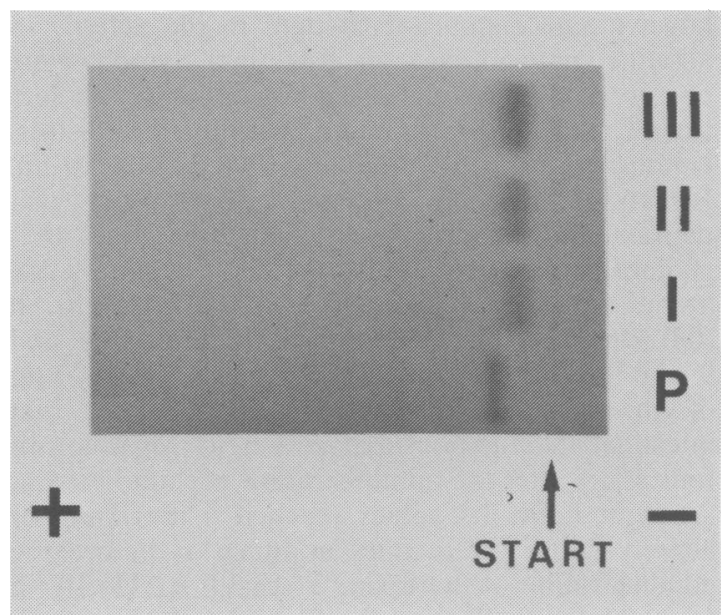

Fig. 2 Iso-enzyme patterns of alkaline phosphatase after agar gel electrophoresis of intestinal lymph in rats. $P$ : placental alkaline phosphatase (marker). I: intestinal lymph of rat before cholera toxin administration. II: intestinal lymph of chlorpromazine-treated rat eight hours after the administration of $100 \mu \mathrm{g}$ of cholera toxin. III: intestinal lymph of rat eight hours after the administration of $100 \mu \mathrm{g}$ of cholera toxin. administration, the alkaline phosphatase activity in intestinal lymph of chlorpromazine-treated rats was not suppressed and was $12 \cdot 8 \pm 1 \cdot 8 \mathrm{KAU} \times 10^{-2} / \mathrm{h}$ with $1000 \mu \mathrm{g}$ of cholera toxin, while at eight hours the activity of lymph intestinal alkaline phosphatase of rats treated with chlorpromazine was not raised and was $12 \cdot 9 \pm 2 \cdot 0 \mathrm{KAU} \times 10^{-2} / \mathrm{h}$ with $1000 \mu \mathrm{g}$ of cholera toxin. Changes of intestinal alkaline phosphatase activity in intestinal lymph after administration of cholera toxin and the inhibitory effect of chlorpromazine on the alkaline phosphatase output is shown in Fig. 3.

\section{Discussion}

There have been several reports of an increase of hepatic alkaline phosphatase caused by administration of cholera toxin. Graybill et al ${ }^{16}$ demonstrated that the intravenous injection of the toxin into dogs produced a rise in serum alkaline phosphatase of hepatic origin. Baker et $a^{17}$ also reported that an intravenously administered cholera toxin led to an increase in hepatic alkaline phosphatase activity in rats and that this increase was mediated by CAMP. We consider, however, that it may be more natural and more important to 


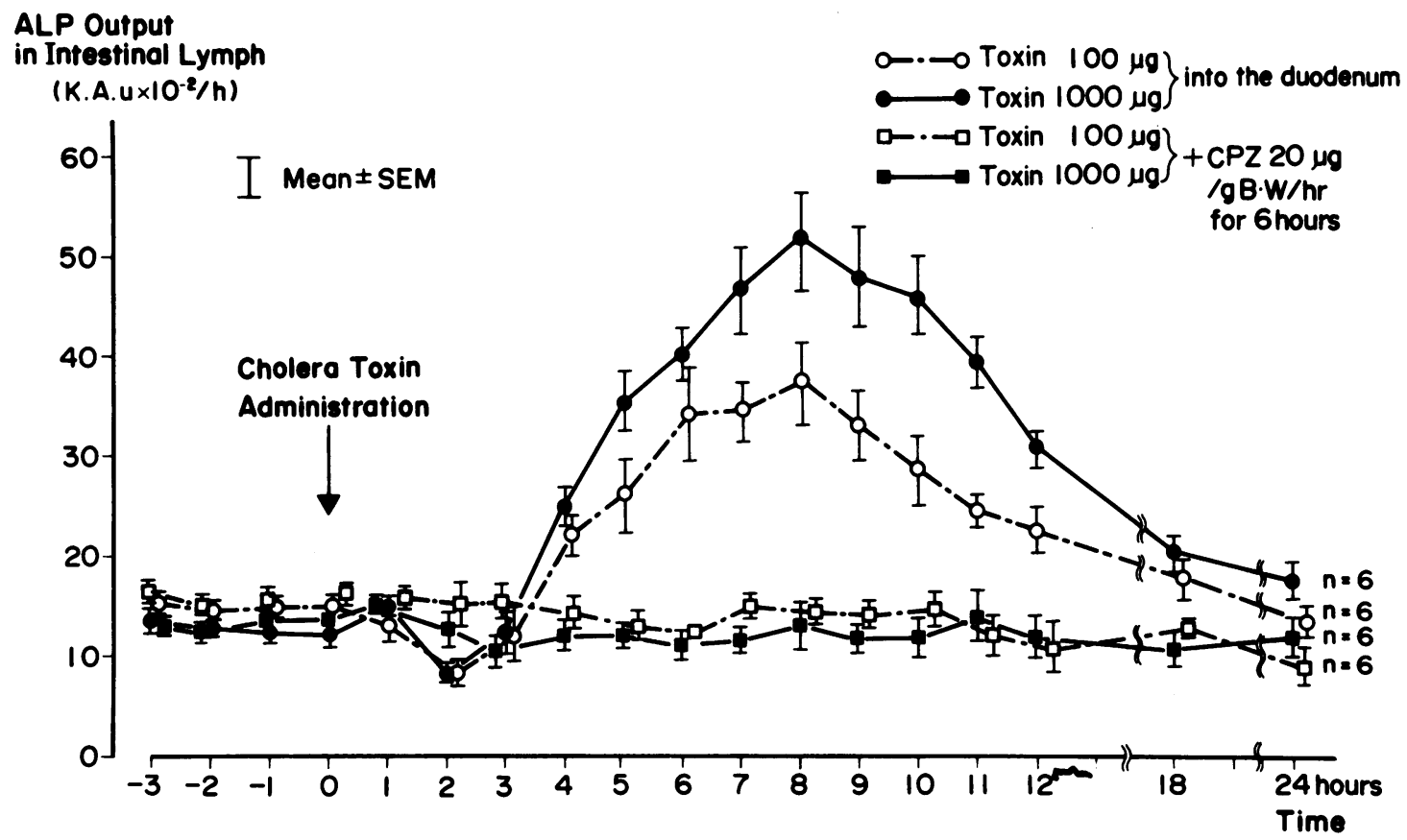

Fig. 3 A time course of intestinal alkaline phosphatase activity (IAP) in intestinal lymph after the administration of cholera toxin to rats: effect of chlorpromazine (CPZ). Cholera toxin $100 \mu \mathrm{g}$ and $1000 \mu \mathrm{g}$ was administered into the duodenum of rats. Lymph was collected hourly for 24 hours and intestinal alkaline phosphatase output was determined. Chlorpromazine $20 \mu \mathrm{g} / \mathrm{g}$ of body weight was injected intramuscularly for six hours into rats.

study the changes of intestinal alkaline phosphatase activity after the oral administration of cholera toxin. Leitch $e$ al have reported that the activity of intestinal alkaline phosphatase is decreased by cholera toxin using rabbit ileal loops, but the time course of enzyme activity was not observed. ${ }^{9}$

In our present study, both intestinal alkaline phosphatase activity in the intestinal mucosa as well as its output into intestinal lymph changed biphasically after the oral administration of cholera toxin. They were inhibited by the first three hours. We cannot clearly discern the exact course of this inhibition from this study. These data suggest, however, that cholera toxin decreases intestinal alkaline phosphatase activity at first by the direct contact of the toxin with this enzyme, by the inhibition of enzyme synthesis in the intestinal mucosa, or by an increase in luminal excretion of stored or newly synthesised intestinal alkaline phosphatase. In contrast, after three hours an increase of intestinal alkaline phosphatase activity in intestinal mucosa as well as in intestinal lymph was observed in our study. These increases are probably attributable to the increased synthesis in the intestinal mucosa as well as the increased release of intestinal alkaline phosphatase into intestinal lymph which are induced by cholera toxin. A number of previous studies have supported the hypothesis that an increase in tissue CAMP levels results in an increase in glycoprotein synthesis. ${ }^{18} 19$

These biphasic changes of intestinal alkaline phosphatase activity brought about by cholera toxin were prevented by the administration of chlorpromazine. There is a possibility that chlorpromazine may prevent the attachment of cholera toxin to the mucosal cell surface. But chlorpromazine is known to inhibit hormonal stimulation of adenylate cyclase in various tissues. ${ }^{20} 21$ Holmgren et al have reported that chlorpromazine is a potential inhibitor of CAMP-mediated intestinal secretion produced by cholera toxin in mice. ${ }^{10} \mathrm{In}$ our study of rats, chlorpromazine also inhibited the rise in CAMP levels produced by cholera toxin in the intestinal mucosa. It is probable, therefore, that the increase of intestinal alkaline phosphatase activity after four hours is mediated by the adenylate-cyclase-CAMP system in the intestinal mucosa.

It is conceivable that the activity of intestinal alkaline phosphatase may play a part in the 
mechanism of diarrhoea produced by cholera toxin. Morita et al have reported that epithelial cell membranes of rat intestinal mucosa have several glycoprotein receptors to cholera toxin other than $\mathrm{GM}_{1}$ ganglioside. ${ }^{4}$ As intestinal alkaline phosphatase is one of the glycoproteins, these data raise a possibility that cholera toxin attaches to intestinal alkaline phosphatase in the intestinal villous membranes when intestinal mucosa is exposed to cholera toxin and an intestinal alkaline phosphatase may play a part when cholera toxin or its subunits are transported across the villous membranes. It is known that protein synthesis in the intestinal mucosa is necessary for the hypersecretion enhanced by the increased levels of CAMP. ${ }^{22}$ The exact way in which an increase in CAMP causes the ion transport of intestinal cells to be altered is, however, poorly understood. Lucid and Cox have demonstrated that cholera toxin increases the amount of phosphate incorporated into the protein fraction of intestinal epithelial cells. ${ }^{23}$ There is therefore the alternative possibility that intestinal alkaline phosphatase may play a part in the phosphorylation of protein in intestinal epithelial cells which results in the state of hypersecretion.

This work was supported in part by the grants from US-Japan Cooperative Medical Science Program Cholera Panel and the Japanese Ministry of Health and Welfare.

\section{References}

1 Schafer DE, Lust WD, Sircar B, Goldberg ND. Elevated concentration of 3:5-cyclic monophosphate in intestinal mucosa after treatment with cholera toxin. Proc Natl Acad Sci USA 1970; 67: 851-6.

2 Gill DM. Mechanism of action of cholera toxin. In: Greengard P, Robison GA, eds. Advances in cyclic nucleotide research. Vol 8. New York: Raven Press, 1977: 85-118.

3 Kimberg DV. Cyclic nucleotides and their role in gastrointestinal secretion. Gastroenterology 1974; 67: 1023-64.

4 Morita A, Tsao D, Kim YS. Identification of cholera toxin binding glycoproteins in rat intestinal microvillus membranes. J Biol Chem 1980; 255: 2549-53.

5 Sherr HP, Mertens RB, Broock R. Cholera toxininduced glycoprotein secretion in rabbit small intestine. Gastroenterology 1979; 77: 18-25.

6 Linscheer WG, Malagelada JR, Fishman WH. Diminished oleic acid absorption in man by $\mathrm{L}$ phenylalanine inhibition of an intestinal phosphohydrolase. Nature (New Biology) 1971; 231: 116-7.

7 Miura S, Asakura H, Miyairi M, Morishita T, Ishii H, Tsuchiya M. Study on the fat absorption and trans- portation into intestinal lymph of rats. Differences in the absorption of saturated and unsaturated long chain fatty acids and the role of intestinal alkaline phosphatase. Jap J Gastroenterol 1979; 76: 871-80.

8 Norman AW, Mircheff AK, Adams TH, Spielvogel A. Studies on the mechanism of action of calciferol III. Vitamin D-induced increase of intestinal brush border alkaline phosphatase activity. Biochim Biophys Acta 1970; 215: 348-59.

9 Leitch GJ, Glinsukon T. Intestinal mucosal epithelial cell electrophoretic mobility and brush border chemistry during experimental cholera. Exp Mol Pathol 1969; 11: 153-62.

10 Holmgren J, Lange S, Lonnröth I. Reversal of cyclic AMP-mediated intestinal secretion in mice by chlorpromazine. Gastroenterology 1978; 75: 1103-8.

11 Lowry $\mathrm{OH}$, Rosebrough NJ, Farr AL, Randall RJ. Protein measurement with the Folin phenol reagent. $J$ Biol Chem 1951; 193: 265-75.

12 Watanabe K, Fishman WH. Application of the stereospecific inhibitor L-phenylalanine to the enzymorphology of intestinal alkaline phosphatase. J Histochem Cytochem 1964; 12: 252-60.

13 Bollman JL. A cage which limits the activity of rats. $J$ Lab Clin Med 1948; 33: 1348.

14 Kind PRN, King EJ. Estimation of plasma phosphatase by determination of hydrolysed phenol with aminoantipyrine. J Clin Pathol 1954; 7: 322-6.

15 Haije WH, Dejong M. Iso-enzyme pattern of serum alkaline phosphatase in agar-gel electrophoresis and their clinical significance. Clin Chim Acta 1963; 8: 620-3.

16 Graybill JR, Kaplan MM, Pierce NF. Hormone-like effects of cholera exotoxin. Clin Res 1970; 18: 454.

17 Baker A, Kaplan M, Kimberg DV. Alkaline phosphatase. Possible induction by cyclic AMP after cholera enterotoxin administration. J Clin Invest 1973; 52: 2928-34.

18 LaMont JT, Ventola A. Stimulation of colonic glycoprotein synthesis by dibutyryl cyclic AMP and theophylline. Gastroenterology 1977; 72: 82-6.

19 Forstner G, Shih M, Lukie B. Cyclic AMP and intestinal glycoprotein synthesis: The effect of $\beta$ adrenergic agents, theophylline, and dibutyryl cyclic AMP. Can J Physiol Pharmacol 1973; 51: 122-9.

20 Wolf $\mathrm{J}$, Jones AB. Inhibition of hormone-sensitive adenyl cyclase by phenothiazines. Proc Natl Acad Sci USA 1970; 65: 454-9.

21 Osnes JB, Christoffersen T, Mørland J, Øye I. Chlorpromazine and hormonal elevation of cyclic AMP contents in turkey erythrocytes and in perfused rat heart and liver. Acta Pharmacol Toxicol 1976; 38: 195-208.

22 Kimberg DV, Field M, Gershon E, Schooley RT, Henderson A. Effect of cycloheximide on the response of intestinal mucosa to cholera enterotoxin. J Clin Invest 1973; 52: 1376-83.

23 Lucid SW, Cox AC. The effect of cholera toxin on the phosphorylation of protein in epithelial cells and their brush borders. Biochem Biophys Res Commun 1972; 49: $1183-6$. 